\title{
The reversal of antineoplastic drug resistance in cancer cells by $\beta$-elemene
}

\author{
Guan-Nan Zhang ${ }^{1 \dagger}$, Charles R. Ashby Jr. ${ }^{1 \dagger}$, Yun-Kai Zhang ${ }^{1}$, Zhe-Sheng Chen ${ }^{1 *}$ and Huiqin Guo ${ }^{2^{*}}$
}

\begin{abstract}
Multidrug resistance (MDR), defined as the resistance of cancer cells to compounds with diverse structures and mechanisms of actions, significantly limits the efficacy of antitumor drugs. A major mechanism that mediates MDR in cancer is the overexpression of adenosine triphosphate (ATP)-binding cassette transporters. These transporters bind to their respective substrates and catalyze their efflux from cancer cells, thereby lowering the intracellular concentrations of the substrates and thus attenuating or even abolishing their efficacy. In addition, cancer cells can become resistant to drugs via mechanisms that attenuate apoptosis and cell cycle arrest such as alterations in the p53, check point kinase, nuclear factor kappa B, and the p38 mitogen-activated protein kinase pathway. In this review, we discuss the mechanisms by which $\beta$-elemene, a compound extracted from Rhizoma zedoariae that has clinical antitumor efficacy, overcomes drug resistance in cancer.
\end{abstract}

Keywords: Rhizoma zedoariae, $\beta$-Elemene, Multidrug resistance

\section{Background}

Curcuma belongs to the Zingiberaceae family and is a medicinal plant that distributes worldwide. The plants of this genus are mainly grown in southeastern Asia, Brazil, and Australia [1]. Recently, approximately 20 Curcuma species have been discovered in China [2]. The Chinese Pharmacopoeia indicates that Rhizoma zedoariae is the dry rhizome derived from Curcuma wenyujin [1], Curcuma phaeocaulis [2], and Curcuma kwangsiensis [3]. Rhizoma zedoariae has been used as an anti-microbial, anti-inflammatory, anti-proliferative, and antitumor drug [3-7]. $\beta$-elemene [(1S,2S,4R)-2,4-diisopropenyl-1-methyl-1-vinylcyclohexane], a naturally occurring compound isolated from Rhizoma zedoariae, is approved for use in Chinese medicine to treat a variety of cancers, including leukemia and brain, breast, prostate, ovarian, cervical, and lung cancers [8-14]. The structure of $\beta$-elemene is shown in Fig. 1. $\beta$-elemene does not produce

\footnotetext{
*Correspondence: chenz@stjohns.edu; guohuiqin2@163.com ${ }^{\dagger}$ Guan-Nan Zhang and Charles R. Ashby Jr. contributed equally ' Department of Pharmaceutical Sciences, College of Pharmacy and Health Sciences, St. John's University, Queens, NY 11439, USA ${ }^{2}$ Department of Thoracic Surgery, Peking Union Medical College Hospital, Beijing 100730, P. R. China

Full list of author information is available at the end of the article
}

significant or problematic toxicity and is well tolerated by patients [12]. It has been postulated that the anticancer effect of $\beta$-elemene is due to the induction of apoptosis and cell cycle arrest $[8,14]$.

Currently used antitumor drugs can produce their therapeutic action via a number of distinct mechanisms. For example, antitumor drugs can (1) damage DNA or inhibit DNA replication, (2) inhibit DNA and RNA synthesis, (3) interfere with RNA transcription, (4) inhibit protein synthesis, (5) interfere with hormone homeostasis, and (6) disrupt cellular microtubules via stabilization or destabilization [15]. However, it is well established that cancer cells can become resistant to many antitumor drugs; this phenomenon is known as multidrug resistance (MDR) [16]. MDR occurs when cancer cells become resistant to a variety of drugs that have distinct structures and mechanisms of action [17]. A number of mechanisms have been reported to produce MDR, including altered activity of specific enzyme systems such as glutathione S-transferase (GST) and topoisomerase, which can attenuate the efficacy of anticancer drugs [18, 19]. In addition, alterations in the levels of proteins that control apoptosis can occur; such alterations decrease the efficacy of anticancer drugs by inducing apoptosis [20]. A well-documented mechanism that produces or elicits MDR is the 


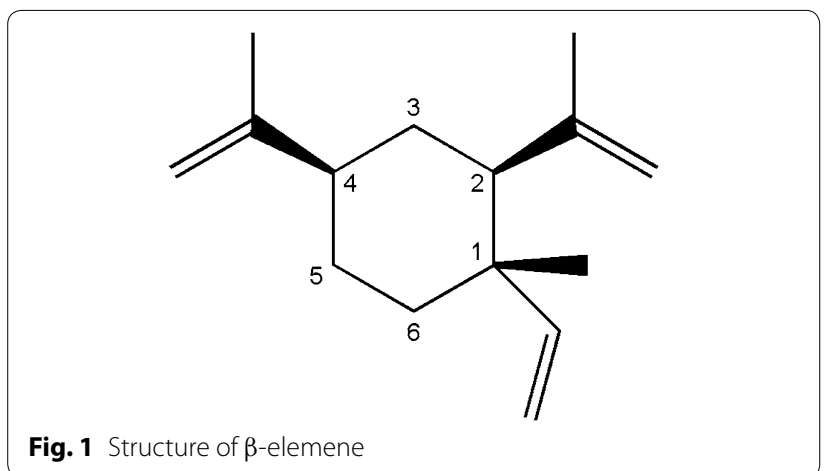

overexpression of adenosine triphosphate (ATP)-binding cassette $(\mathrm{ABC})$ transporters, such as the ABCB1 (P-glycoprotein, $\mathrm{P}$-gp/MDR1), ABCCs [multidrug resistanceassociated proteins (MRPs)], and ABCG2 transporters (BCRP/MXR/ABCP) [21]. These transporters use energy obtained from the hydrolysis of ATP to remove or efflux compounds from cancer cells, thereby significantly lowering their intracellular concentrations and attenuating their efficacy [22]. The ABC transporter P-gp is expressed by cancer cells derived from epithelial cells of the colon, liver, adrenal gland, and pancreas and has been reported to produce resistance to a broad spectrum of anticancer drugs, including anthracyclines, vinca alkaloids, etoposide, and taxanes [23-26]. In addition, the overexpression of other $A B C$ transporters, such as ABCCs and ABCG2, can also produce MDR in cancer cells [21, 27-29]. Numerous studies indicate that the blockade of the efflux function of specific $A B C$ transporters by various compounds can resensitize resistant cancer cells to specific antitumor drugs by increasing the intracellular concentration of these transporters. However, this approach has been hampered because inhibitors of the efflux activity of $A B C$ transporters have produced severe adverse effects and toxic drug-drug interactions [30].

One approach that has been used to overcome MDR in cancer cells is to find or synthesize compounds that can block the efflux action of the $\mathrm{ABC}$ transporters without producing significant toxic effects [31]. Over the last four decades, three generations of $\mathrm{ABC}$ transporter inhibitors have been developed in an attempt to overcome MDR in cancer cells. One of the first-generation drugs, verapamil, a calcium channel blocker, was the first drug shown to inhibit the efflux function of P-gp [32]. However, clinical data indicated that verapamil produced significant toxic effects at concentrations required to overcome P-gp-mediated resistance [33]. In addition, verapamil and other first-generation compounds were shown to inhibit the activities of various cytochrome P450 (CYP450) enzymes, thereby increasing the likelihood of adverse and toxic drug-drug interactions
[34-36]. To overcome the aforementioned limitations of first-generation compounds, second-generation compounds were developed [37, 38]. Second-generation P-gP modulators included PSC833 and biricodar (VX-710). Compared with first-generation compounds, these P-gp inhibitors were reported to be more potent in reversing MDR and less toxic [37, 39]. Among second-generation P-gp modulators, PSC833 was the most well characterized, and it was used in clinical trials in combination with doxorubicin [DOX, also known as adriamycin (ADM)], vincristine, vinblastine, paclitaxel (TAX), or mitoxantrone to treat MDR cancer [37, 39]. PSC833 alone did not produce significant adverse effects, but it increased the likelihood of toxic effects when used with antitumor drugs. For example, a significant pharmacokinetic interaction was observed when PSC833 was administered in combination with DOX and TAX $[40,41]$, thus requiring a reduction in the doses of the anticancer drugs. It was subsequently shown that second-generation P-gp inhibitors significantly decreased the excretion of various drugs, thereby increasing the incidence of significant adverse effects [41]. In addition, to overcome the problematic drug-drug interactions, the doses of these drugs had to be decreased, which attenuated their efficacy.

Third-generation P-gp inhibitors such as tariquidar (XR9576), laniquidar (R101933), and LY335979, were developed to overcome the limitations associated with second-generation inhibitors [42-45]. Although thirdgeneration P-gp inhibitors were significantly efficacious in vitro, these compounds are not used clinically because in vivo and preclinical studies indicated a lack of efficacy and/or significant adverse effects [46].

It has been well-established that certain compounds extracted from various natural sources have antitumor efficacy [47, 48]. However, relatively few studies have reported the effects of naturally derived compounds on the activities and functions of $\mathrm{ABC}$ transporters. Given the important role of $\mathrm{ABC}$ transporters in mediating MDR, we recently reported the in vitro effect of the compound $\beta$-elemene, extracted from the plant Rhizoma zedoariae, on MDR in cancer cells [49]. In addition, this compound may overcome MDR via other mechanisms [50]. Therefore, in this review, we discuss the mechanisms by which $\beta$-elemene surmounts MDR. Figure 2 illustrates the mechanisms by which $\beta$-elemene mediates the reversal of MDR in cancer cells.

\section{Antitumor efficacy of $\beta$-elemene}

$\beta$-Elemene has been purported to inhibit the proliferation of cancer cells by inducing apoptotic cell death and cell cycle arrest $[8,51,52]$. The dysfunction or blockade of apoptosis has been proposed to play a role in abnormal cell proliferation, thus initiating the carcinogenic 


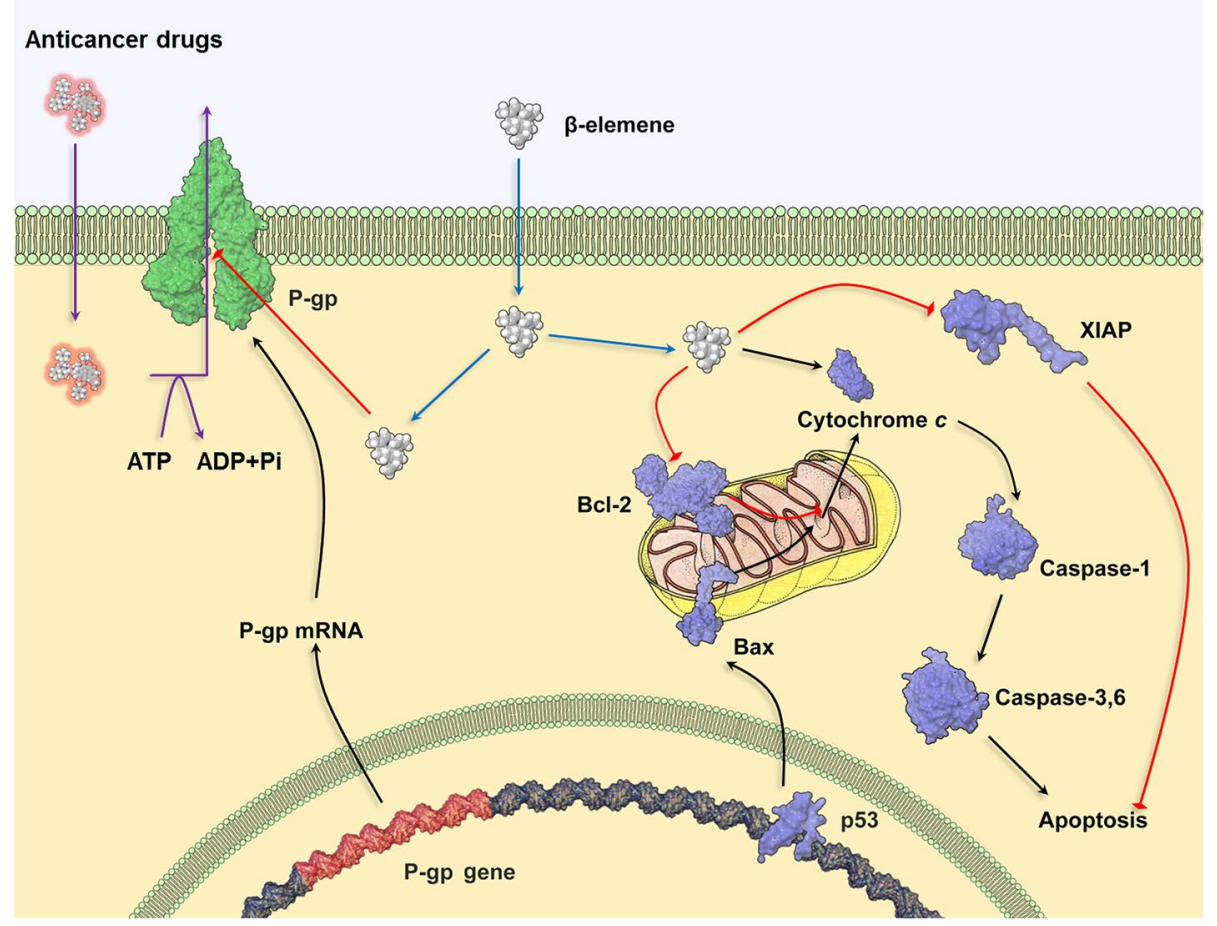

Fig. 2 A schematic model of the mechanisms for $\beta$-elemene-induced apoptosis and augmentation of the efficacy of anticancer drugs. $\beta$-elemene may enhance the therapeutic effect of anticancer drugs by blocking the substrate efflux function (purple arrows) of the multidrug-resistant transporter P-glycoprotein (P-gp). In addition, it has been proposed that $\beta$-elemene may affect multiple pathways to produce apoptosis in tumor cells. Black arrows indicate stimulatory modifications, whereas red arrows indicate inhibitory modifications. XIAP X-linked inhibitor of apoptosis protein, ATP adenosine triphosphate, ADP adenosine diphosphate

processes involved in tumor proliferation, angiogenesis, and metastasis [53]. Apoptosis can be initiated by the activation of the intrinsic and extrinsic pathways. The activation of the intrinsic pathway disrupts the balance between pro-survival proteins (e.g., $\mathrm{Bcl}-2$ and $\mathrm{Bcl}-\mathrm{xL}$ ) and pro-apoptotic proteins of the Bcl-2 family (e.g., Bax and Bak), which triggers the release of cytochrome $c$ from the mitochondrial outer membrane [54]. In contrast, the extrinsic pathway is activated by the binding of specific molecules to death receptors such as FAS receptor (FasR), tumor necrosis factor receptor 1 (TNFR1), death receptor 3 (DR3), and death receptor 4/death receptor 5 (DR4/DR5) [55]. Numerous studies indicate that apoptosis is an important therapeutic target for cancer treatment [56]. There are studies indicating that $\beta$-elemene affects the apoptotic process in cancer cells. For example, $\beta$-elemene significantly inhibits the growth and proliferation of various types of T24 bladder cancer cell lines by decreasing the expression of the anti-apoptotic proteins Mta-1, Survivin, and Bcl-xL [57]. In addition, $\beta$-elemene significantly inhibits the proliferation of lung and prostate cancer cells by increasing the release of cytochrome $c$ and the activation of caspases-3, -7, and -9 and of
poly(ADP-ribose) polymerase (PARP) and by decreasing the expression of Bcl-2 [58].

There are data suggesting that $\beta$-elemene triggers cell cycle arrest by activating the p38 mitogen-activated protein kinase (MAPK) pathway. For example, in C6 glioblastoma cells, $\beta$-elemene significantly increases the fraction of $C 6$ cells at the $G_{0} / G_{1}$ phase [48]. The cell cycle-arresting action of $\beta$-elemene was associated with an increase in the phosphorylation of p38 MAPK, whereas this effect was reversed by the inhibition of p38 MAPK [52]. Furthermore, in non-small cell lung cancer (NSCLC) and epithelial cell lines, $\beta$-elemene significantly arrested the cell cycle at the $G_{2}-M$ phase by decreasing the expression of Cyclin B1 and phospho-Cdc2 (Thr-161) and by increasing the expression of P27 (kip) and phospho-Cdc (Tyr-15) [11]. Recently, Zhao et al. [59] reported that $\beta$-elemene can significantly inhibit the proliferation of NSCLC cells by inhibiting extracellular signal-regulated kinases (ERK1/2) and the adenosine monophosphate-activated protein kinase $\alpha(\mathrm{AMPK} \alpha)$-mediated transcription factor $\mathrm{Sp} 1$ and then by decreasing the protein expression of DNA (cytosine-5)-methyltransferase 1 (DNMT1). In addition, the action of $\beta$-elemene on the 
proliferation of NSCLC cells was reversed by the overexpression of DNMT1, and the inhibition of Akt signaling and DNMT1 expression by metformin can potentiate the effects of $\beta$-elemene [59]. In A2780/CP ovarian carcinoma cells (which are resistant to cisplatin), $\beta$-elemene induces cell cycle arrest at the $\mathrm{G}_{2} / \mathrm{M}$ phase by decreasing the expression of $\mathrm{B} 1$ and $\mathrm{Cdc} 2$ and by increasing the expression of $\mathrm{p} 53$, p27, and growth arrest and DNA-damage-inducible protein (GADD45) [8].

It is well documented that radiation therapy plays an important role in the treatment of radiation-sensitive tumors [60]. The overexpression of peroxiredoxin 1 (Prx$1)$, a critical regulator of redox in cancer cells, has been reported to abrogate the response of cancer cells to radiation therapy [60]. Thus, reducing the expression of Prx-1 is a promising way to resensitize tumor cells to radiation therapy. In this study, Li et al. [60] demonstrated that $45 \mathrm{mg} / \mathrm{kg} \beta$-elemene restores the sensitivity of A549 tumor cells to radiation. Reverse transcription-polymerase chain reaction (RT-PCR) and Western blotting assays indicated that the potentiation of radiation therapy by $\beta$-elemene was mediated by the down-regulation of Prx-1.

\section{Reversal of MDR by $\beta$-elemene Reversal of $A B C$ transporter-mediated MDR by $\beta$-elemene}

As mentioned above, one of the well-documented mechanisms responsible for MDR is the overexpression of P-gp. Therefore, our laboratory conducted a study to examine the in vitro effect of $\beta$-elemene on P-gp-induced MDR in drug-resistant and non-drug-resistant parental cell lines [49]. We determined the effect of $\beta$-elemene on the cytotoxic effects of the antitumor drugs colchicine, vinblastine, and TAX (P-gp substrates) in parenteral KB-3-1 cells and in $\mathrm{KB}-\mathrm{C} 2$ cells overexpressing $\mathrm{P}$-gp. $\beta$-elemene $(100 \mu \mathrm{mol} / \mathrm{L})$ significantly increased the efficacy (i.e., the cytotoxicity) of P-gp substrate drugs in KB-C2 cells but not in parenteral KB-3-1 cells. For example, the responses to TAX, vinblastine, and colchicine in KB-C2 cells were 648-, 11.7-, and 720-fold lower, respectively, than those in parental KB-3-1 cells. $\beta$-elemene $(100 \mu \mathrm{mol} / \mathrm{L})$ significantly lowered the magnitude of resistance to TAX, vinblastine, and colchicine (by 4.6-, 5.4-, and 1.1-fold, respectively) in KB-C2 cells. The results of accumulation and efflux assays indicated that $\beta$-elemene potentiated the cytotoxic action of the antitumor drugs that were P-gp substrates by blocking their efflux via P-gp, thereby increasing their intracellular concentrations (by 3.6 -fold) in $\mathrm{KB}-\mathrm{C} 2$ cells overexpressing $\mathrm{P}$-gp. It is possible that $\beta$-elemene could potentiate the actions of antitumor drugs by decreasing the expression of P-gp protein. However, the incubation of $\mathrm{KB}-\mathrm{C} 2$ with $\beta$-elemene for 24,48 , or $72 \mathrm{~h}$ did not significantly alter the expression of P-gp. Overall, our results suggested that $\beta$-elemene potentiated the actions of P-gp substrate drugs by inhibiting the efflux function of P-gp. Our study did not rule out the possibility that $\beta$-elemene could produce its potentiating action by decreasing the insertion of the P-gp transporter into the cell membrane.

Similar to our findings, $\mathrm{Xu}$ et al. [61] reported that $\beta$-elemene $(30 \mu \mathrm{mol} / \mathrm{L})$ significantly potentiated (6.38fold) the action of DOX in DOX-resistant MCF-7 cells. Furthermore, it was shown that $\beta$-elemene $(30 \mu \mathrm{mol} / \mathrm{L})$ significantly increased the intracellular accumulation of DOX and the compound Rh123, which is a substrate of $\mathrm{P}$-gp. Interestingly, Xu et al. [61] showed that $\beta$-elemene $(30 \mu \mathrm{mol} / \mathrm{L})$ significantly decreased P-gp protein expression, suggesting that the action of $\beta$-elemene is due in part to this mechanism. This finding was in contrast to our results indicating that $\beta$-elemene did not significantly alter the expression of $\mathrm{P}$-gp. The exact explanation for this discrepancy is unknown, but it may be due to differences in the cell lines used (MCF-7/DOX versus KB-C2 and HEK293/ABCB1) [61].

$\beta$-Elemene significantly increases the suppressive effect of DOX and docetaxel (Doc) on the growth and proliferation of the resistant MCF-7/Adr and MCF-7/Doc breast cancer cell lines [7]. $\beta$-elemene may attenuate MDR by influencing MDR-related microRNA expression and subsequently regulating the target genes phosphatase and tensin homolog (PTEN) and P-gp, which are responsible for the proliferation of resistant breast cancer cells [7].

\section{$\beta$-Elemene reverses MDR by promoting apoptosis of resistant cancer cells}

It is known that mechanisms that inhibit or attenuate the induction of cancer cell apoptosis produce resistance to certain antitumor drugs [20]. The induction of apoptosis by antitumor drugs has been shown to trigger a significant generation of reactive oxygen species (ROS) and disruption of mitochondrial membrane potential [62]. Numerous studies suggest that apoptosis involves the complex interaction and regulation of many genes and proteins [56]. The suppressor gene $p 53$ is a key mediator of apoptosis-induced cellular transformation [63, 64]. Following DNA damage by certain antitumor drugs, $p 53$ is activated, resulting in $G_{1}$ phase arrest and, subsequently, apoptosis $[56,65]$. Thus, the loss of $p 53$ or inactivation of the p53 pathway could contribute to drug resistance $[63,66]$. In addition, proteins whose expression is regulated by $p 53$, such as B cell lymphoma-2 (Bcl-2) and Bax, are also involved in mediating resistance to antitumor drugs [67]. Indeed, proteins categorized as anti-apoptotic $\mathrm{Bcl}-2$ members are transcriptionally up-regulated in cancer cells and are associated with resistance to the antitumor drugs DOX, TAX, cisplatin, mitoxantrone, and 
etoposide. Thus, the down-regulation (as well as inactivation) of anti-apoptotic Bcl-2 proteins can augment apoptosis, thereby increasing the efficacy of antitumor drugs in resistant cancer cells. For example, it has been postulated that the reversal mechanism of $\beta$-elemene $(6 \mu \mathrm{g} / \mathrm{mL})$ in the ADM-resistant human breast cancer cell line MCF-7/ADM may result from a decrease in the expression of Bcl-2 [68]. In the parental ovarian cancer cell line A2780 and the cisplatin-resistant cell line A2780/ CP70, $\beta$-elemene $(0.6 \mu \mathrm{mol} / \mathrm{L})$ significantly enhanced cisplatin cytotoxicity in the drug-resistant cell lines (by 60 -fold) [69]. These results suggested that $\beta$-elemene acts by abrogating the expression of the excision pathway that repairs protein cross-complementation group 1 (ERCC1) protein. In addition, the level of the X-linked inhibitor of apoptosis protein (XIAP) is significantly decreased by $\beta$-elemene $(0.6 \mu \mathrm{mol} / \mathrm{L})[69,70]$. In ovarian carcinoma cells resistant to cisplatin, the combination of $\beta$-elemene and cisplatin can stimulate the activity of caspases- $3,-8$, and -9 as well as the cleavage of caspase- 9 , whereas the expression of Bcl-2 and Bcl-xL was decreased [70]. Thus, based on the aforementioned results, $\beta$-elemene restores the sensitivity of resistant ovarian cancer cells to cisplatin by attenuating DNA repair activity and promoting apoptosis. Furthermore, $\beta$-elemene significantly augments the antitumor activity of cisplatin in human bladder cancer cells by inducing cell apoptosis via a caspase-dependent mechanism [69, 70]. Wang et al. [11] reported that $\beta$-elemene significantly augments cisplatin-induced inhibition of the growth of a NSCLC cell line by inducing cell cycle arrest. Similarly, $\beta$-elemene significantly increased the suppressive effect of cisplatin on the growth and proliferation of NSCLC H460 and A549 cell lines [14]. It was postulated that the potentiation of the efficacy of cisplatin by $\beta$-elemene was due to inducing cell cycle arrest in NSCLC cells at the $G_{2} / M$ phase by increasing checkpoint kinase 2 (CHK2) expression and reducing Cdc2 activity [71]. In addition, the combination of $\beta$-elemene and cisplatin significantly decreased the protein levels of Cyclin $\mathrm{B} 1$ and $\mathrm{Cdc} 25 \mathrm{C}$ and increased the levels of P21, P27, and GADD45 in cancer cells [71]. Furthermore, a metaanalysis of clinical data suggested that the combination of $\beta$-elemene and cisplatin was more efficacious than cisplatin alone in treating NSCLC and significantly improved the quality of life of the patients [22].

Endocrine therapy plays a critical role in the treatment of estrogen receptor (ER)-positive breast cancer, and the lack of ER expression is associated with a decrease in the efficacy of endocrine-based therapy [72]. In MCF7/ TAX cell lines, which do not express ER- $\alpha, 10 \mu \mathrm{g} / \mathrm{mL}$ of $\beta$-elemene restored the sensitivity of MCF7/TAM cell lines to TAX. RT-PCR and Western blotting assays indicated that the reversal of TAX resistance by $\beta$-elemene was mediated by up-regulating the expression of $E R-\alpha$ mRNA via the MAPK pathway [73].

The protein nuclear factor- $\kappa \mathrm{B}(\mathrm{NF}-\kappa \mathrm{B})$ is associated with the development of chemo-resistance in various cancer cells by inducing the overexpression of anti-apoptotic proteins [74]. Thus, inhibition of NF-kB-mediated responses may be a promising strategy for potentiating the response to antitumor drugs. The incubation of ADM-resistant cells (SGC7901/ADM gastric cancer cells) with $\beta$-elemene significantly decreased the expression of NF-кB [75]. In addition, $\beta$-elemene significantly increased the apoptotic rate of SGC7901/ADM cells by inhibiting or attenuating NF- $\kappa$ B activity [75].

\section{$\beta$-Elemene reverses MDR by reducing the stemness of cancer cells}

Glioblastoma stem-like cells (GSCs) play an important role in tumor development, recurrence, and chemoresistance [76]. It has been postulated that impairing stemness and enhancing differentiation could decrease GSC-associated chemo-resistance [76]. Fu et al. [75] reported that $\beta$-elemene significantly impaired the stemness of GSC spheres, dispersed GSC spheres, and reduced the proliferation of GSCs in vitro and in vivo. In addition, they also found that $\beta$-elemene in GSC spheres and xenografts can significantly decrease the expression of CD133 and ABCG2 and increase the expression of glial fibrillary acidic protein (GFAP). Furthermore, $\beta$-elemene can also restore the sensitivity of GSCs to temozolomide [76]. The $\beta$-elemene-mediated potentiation of the efficacy of temozolomide on glioblastoma cells results from activation of the glia maturation factor $\beta$ (GMF $\beta$ )/MAPK $3 / 6 /$ p38 pathway [77]. In addition, it has been reported that the antitumor effect of $\beta$-elemene was also mediated by GMF $\beta$-dependent inactivation of the ERK1/2$\mathrm{Bcl}-2 /$ survivin pathway, which suggests that $\beta$-elemene is a promising chemosensitizer for temozolomide against glioblastoma tumors [77].

In addition, the combination of $\beta$-elemene and TAX, compared with TAX alone, significantly inhibited the proliferation of MB-468 cells by decreasing the expression of Cyclin B1 and increasing the expression of P27 (kip1) [78]. Furthermore, the combination of $\beta$-elemene (20 or $50 \mu \mathrm{g} / \mathrm{mL}$ ) and etoposide phosphate (VP-16, $15 \mu \mathrm{g} / \mathrm{mL}$ ) increased the likelihood of apoptosis compared with VP-16 alone (16.57 or 21.98 vs. $6.25 \%$ ) [79]. The potentiation of the efficacy of VP-16 by $\beta$-elemene may be mediated by the increase of Bax, p53, and p21 and the suppression of Cyclin D1 [79].

\section{Conclusions}

$\beta$-Elemene plays an important role in overcoming MDR via multiple mechanisms. It is possible that the reversal 
action of $\beta$-elemene could result from (1) a blockade of the efflux function of P-gp, (2) a decrease in the protein levels of P-gp, (3) an induction of apoptosis or cell cycle arrest, or (4) a decrease in NF- $\kappa B$ signaling activity. Finally, it may be of interest to determine if $\beta$-elemene alters the expression and/or efflux activity of other $A B C$ transporters. Currently, the in vitro and in vivo data obtained for $\beta$-elemene suggest that it may be useful in treating certain MDR cancers. However, controlled clinical trials will be required to determine if $\beta$-elemene will significantly increase the efficacy of various chemotherapeutic drugs in reversing MDR in cancer patients.

\section{Authors' contributions}

GNZ, RAC, and ZSC conceived the concept and contributed to writing the manuscript. YKZ, RAC, and HG contributed to revising the manuscript. All authors read and approved the final manuscript.

\section{Author details \\ ${ }_{1}^{1}$ Department of Pharmaceutical Sciences, College of Pharmacy and Health Sciences, St. John's University, Queens, NY 11439, USA. ${ }^{2}$ Department of Tho- racic Surgery, Peking Union Medical College Hospital, Beijing 100730, P. R. China.}

\section{Acknowledgements}

This work was supported by St. John's University Research Seed Grant (No. 579-1110-7002) to Zhe-Sheng Chen.

\section{Compliance with ethical guidelines}

\section{Competing interests}

The authors declare that they have no competing interests.

Received: 11 June 2015 Accepted: 26 July 2015

Published online: 14 September 2015

\section{References}

1. Lim CB, Ky N, Ng HM, Hamza MS, Zhao Y. Curcuma wenyujin extract induces apoptosis and inhibits proliferation of human cervical cancer cells in vitro and in vivo. Integr Cancer Ther. 2010;9(1):36-49. doi:10.1177/1534735409359773.

2. Lai EY, Chyau CC, Mau JL, Chen CC, Lai YJ, Shih CF, et al. Antimicrobial activity and cytotoxicity of the essential oil of Curcuma zedoaria. Am J Chin Med. 2004;32(2):281-90. doi:10.1142/S0192415X0400193X.

3. Tohda C, Nakayama N, Hatanaka F, Komatsu K. Comparison of anti-inflammatory activities of six Curcuma rhizomes: a possible curcuminoid-independent pathway mediated by Curcuma phaeocaulis extract. Evid Based Complement Alternat Med. 2006;3(2):255-60. doi:10.1093/ecam/nel008.

4. Maheshwari RK, Singh AK, Gaddipati J, Srimal RC. Multiple biological activities of curcumin: a short review. Life Sci. 2006;78(18):2081-7. doi:10.1016/j.lfs.2005.12.007.

5. Makabe H, Maru N, Kuwabara A, Kamo T, Hirota M. Anti-inflammatory sesquiterpenes from Curcuma zedoaria. Nat Prod Res. 2006;20(7):680-5. doi:10.1080/14786410500462900.

6. Park SD, Jung JH, Lee HW, Kwon YM, Chung KH, Kim MG, et al. Zedoariae rhizoma and curcumin inhibits platelet-derived growth factor-induced proliferation of human hepatic myofibroblasts. Int Immunopharmacol. 2005:5(3):555-69. doi:10.1016/j.intimp.2004.11.003.

7. Zhang J, Zhang H, Chen L, da Sun W, Mao C, Chen W, et al. $\beta$-Elemene reverses chemoresistance of breast cancer via regulating MDR-related microRNA expression. Cell Physiol Biochem. 2014;34(6):2027-37. doi:10.1159/000366398.

8. Lee RX, Li QQ, Reed E. $\beta$-Elemene effectively suppresses the growth and survival of both platinum-sensitive and -resistant ovarian tumor cells. Anticancer Res. 2012;32(8):3103-13.
9. Zheng S, Yang H, Zhang S, Wang X, Yu L, Lu J, et al. Initial study on naturally occurring products from traditional Chinese herbs and vegetables for chemoprevention. J Cell Biochem Suppl. 1997;27:106-12.

10. Zhou HY, Shen JK, Hou JS, Qiu YM, Luo QZ. Experimental study on apoptosis induced by elemene in glioma cells. Ai Zheng. 2003;22(9):959-63 (in Chinese).

11. Wang G, Li X, Huang F, Zhao J, Ding H, Cunningham C, et al. Antitumor effect of beta-elemene in non-small-cell lung cancer cells is mediated via induction of cell cycle arrest and apoptotic cell death. Cell Mol Life Sci. 2005;62(7-8):881-93. doi:10.1007/s00018-005-5017-3.

12. Li X, Wang G, Zhao J, Ding H, Cunningham C, Chen F, et al. Antiproliferative effect of beta-elemene in chemoresistant ovarian carcinoma cells is mediated through arrest of the cell cycle at the G2-M phase. Cell Mol Life Sci. 2005;62(7-8):894-904. doi:10.1007/s00018-005-5027-1.

13. Zhao J, Li QQ, Zou B, Wang G, Li X, Kim JE, et al. In vitro combination characterization of the new anticancer plant drug beta-elemene with taxanes against human lung carcinoma. Int J Oncol. 2007;31(2):241-52.

14. Li QQ, Wang G, Zhang M, Cuff CF, Huang L, Reed E. beta-Elemene, a novel plant-derived antineoplastic agent, increases cisplatin chemosensitivity of lung tumor cells by triggering apoptosis. Oncol Rep. 2009;22(1):161-70.

15. Kishi S, Ueda T. Chemotherapy. Nihon Rinsho. 2014;72(3):462-7 (in Japanese).

16. Gottesman MM. How cancer cells evade chemotherapy: sixteenth Richard and Hinda Rosenthal Foundation Award Lecture. Cancer Res. 1993;53(4):747-54.

17. Gillet JP, Gottesman MM. Mechanisms of multidrug resistance in cancer. Methods Mol Biol. 2010;596:47-76. doi:10.1007/978-1-60761-416-6_4.

18. Seitz G, Bonin M, Fuchs J, Poths S, Ruck P, Warmann SW, et al. Inhibition of glutathione-S-transferase as a treatment strategy for multidrug resistance in childhood rhabdomyosarcoma. Int J Oncol. 2010;36(2):491-500.

19. Lewis AD, Forrester LM, Hayes JD, Wareing CJ, Carmichael J, Harris AL, et al. Glutathione S-transferase isoenzymes in human tumours and tumour derived cell lines. Br J Cancer. 1989;60(3):327-31.

20. Reed JC. Regulation of apoptosis by bcl-2 family proteins and its role in cancer and chemoresistance. Curr Opin Oncol. 1995;7(6):541-6.

21. van Veen $H W$, Konings WN. The $A B C$ family of multidrug transporters in microorganisms. Biochim Biophys Acta. 1998;1365(1-2):31-6.

22. Wang B, Peng XX, Sun R, Li J, Zhan XR, Wu LJ, et al. Systematic review of beta-elemene injection as adjunctive treatment for lung cancer. Chin J Integr Med. 2012;18(11):813-23. doi:10.1007/s1 1655-012-1271-9.

23. Roninson IB, Chin JE, Choi KG, Gros P, Housman DE, Fojo A, et al. Isolation of human mdr DNA sequences amplified in multidrug-resistant KB carcinoma cells. Proc Natl Acad Sci USA. 1986;83(12):4538-42.

24. Van der Bliek AM, Baas F, Ten Houte de Lange T, Kooiman PM, Van der Velde-Koerts T, Borst P. The human mdr3 gene encodes a novel P-glycoprotein homologue and gives rise to alternatively spliced mRNAs in liver. EMBO J. 1987;6(11):3325-31.

25. de Bruijn MH, Van der Bliek AM, Biedler JL, Borst P. Differential amplification and disproportionate expression of five genes in three multidrug-resistant Chinese hamster lung cell lines. Mol Cell Biol. 1986;6(12):4717-22.

26. Gros P, Raymond M, Bell J, Housman D. Cloning and characterization of a second member of the mouse mdr gene family. Mol Cell Biol. 1988;8(7):2770-8.

27. Cole SP, Bhardwaj G, Gerlach JH, Mackie JE, Grant CE, Almquist KC, et al. Overexpression of a transporter gene in a multidrug-resistant human lung cancer cell line. Science. 1992;258(5088):1650-4.

28. Guo Y, Kotova E, Chen ZS, Lee K, Hopper-Borge E, Belinsky MG, et al. MRP8, ATP-binding cassette C11 (ABCC11), is a cyclic nucleotide efflux pump and a resistance factor for fluoropyrimidines $2^{\prime}, 3^{\prime}$-dideoxycytidine and 9'-(2'-phosphonylmethoxyethyl)adenine. J Biol Chem. 2003;278(32):29509-14. doi:10.1074/jbc.M304059200.

29. Robert J, Jarry C. Multidrug resistance reversal agents. J Med Chem. 2003;46(23):4805-17. doi:10.1021/jm030183a.

30. Krishna R, Mayer LD. Liposomal doxorubicin circumvents PSC 833-free drug interactions, resulting in effective therapy of multidrug-resistant solid tumors. Cancer Res. 1997;57(23):5246-53.

31. Wu CP, Calcagno AM, Ambudkar SV. Reversal of ABC drug transportermediated multidrug resistance in cancer cells: evaluation of current strategies. Curr Mol Pharmacol. 2008;1 (2):93-105. 
32. Tsuruo T, lida H, Tsukagoshi S, Sakurai Y. Overcoming of vincristine resistance in P388 leukemia in vivo and in vitro through enhanced cytotoxicity of vincristine and vinblastine by verapamil. Cancer Res. 1981:41(5):1967-72.

33. Ozols RF, Cunnion RE, Klecker RW Jr, Hamilton TC, Ostchega Y, Parrillo JE, et al. Verapamil and adriamycin in the treatment of drug-resistant ovarian cancer patients. J Clin Oncol. 1987;5(4):641-7.

34. Dantzig AH, de Alwis DP, Burgess M. Considerations in the design and development of transport inhibitors as adjuncts to drug therapy. Adv Drug Deliv Rev. 2003;55(1):133-50.

35. Tsuruo T, lida H, Tsukagoshi S, Sakurai Y. Potentiation of vincristine and adriamycin effects in human hemopoietic tumor cell lines by calcium antagonists and calmodulin inhibitors. Cancer Res. 1983:43(5):2267-72.

36. Shukla S, Chen ZS, Ambudkar SV. Tyrosine kinase inhibitors as modulators of $A B C$ transporter-mediated drug resistance. Drug Resist Updat. 2012;15(1-2):70-80. doi:10.1016/j.drup.2012.01.005.

37. Boesch D, Muller K, Pourtier-Manzanedo A, Loor F. Restoration of daunomycin retention in multidrug-resistant P388 cells by submicromolar concentrations of SDZ PSC 833, a nonimmunosuppressive cyclosporin derivative. Exp Cell Res. 1991;196(1):26-32.

38. Germann UA, Shlyakhter D, Mason VS, Zelle RE, Duffy JP, Galullo V, et al. Cellular and biochemical characterization of VX-710 as a chemosensitizer: reversal of P-glycoprotein-mediated multidrug resistance in vitro. Anticancer Drugs. 1997;8(2):125-40.

39. Filipski E, Berland E, Ozturk N, Guettier C, van der Horst GT, Levi F, et al. Optimization of irinotecan chronotherapy with P-glycoprotein inhibition. Toxicol Appl Pharmacol. 2014;274(3):471-9. doi:10.1016/j. taap.2013.12.018.

40. Aouali N, El Btaouri H, Dumontet C, Eddabra L, Malagarie-Cazenave S, Madoulet C, et al. Accumulation of lactosylceramide and overexpression of a PSC833-resistant P-glycoprotein in multidrug-resistant human sarcoma cells. Oncol Rep. 2011;25(4):1161-7. doi:10.3892/ or.2011.1180

41. Lhomme C, Joly F, Walker JL, Lissoni AA, Nicoletto MO, Manikhas GM, et al. Phase III study of valspodar (PSC 833) combined with paclitaxel and carboplatin compared with paclitaxel and carboplatin alone in patients with stage IV or suboptimally debulked stage III epithelial ovarian cancer or primary peritoneal cancer. J Clin Oncol. 2008;26(16):2674-82. doi:10.1200/JCO.2007.14.9807

42. Muller H, Pajeva IK, Globisch C, Wiese M. Functional assay and structureactivity relationships of new third-generation P-glycoprotein inhibitors. Bioorg Med Chem. 2008;16(5):2448-62. doi:10.1016/j.bmc.2007.11.057.

43. Morschhauser F, Zinzani PL, Burgess M, Sloots L, Bouafia F, Dumontet C. Phase I/II trial of a P-glycoprotein inhibitor, Zosuquidar. $3 \mathrm{HCl}$ trihydrochloride (LY335979), given orally in combination with the CHOP regimen in patients with non-Hodgkin's lymphoma. Leuk Lymphoma. 2007:48(4):708-15. doi:10.1080/10428190701190169.

44. van Zuylen L, Sparreboom A, van der Gaast A, Nooter K, Eskens FA, Brouwer $E$, et al. Disposition of docetaxel in the presence of P-glycoprotein inhibition by intravenous administration of R101933. Eur J Cancer. 2002;38(8):1090-9.

45. Guns ES, Bullock PL, Reimer ML, Dixon R, Bally M, Mayer LD. Assessment of the involvement of CYP3A in the vitro metabolism of a new modulator of MDR in cancer chemotherapy, OC144-193, by human liver microsomes. Eur J Drug Metab Pharmacokinet. 2001;26(4):273-82.

46. Kim TE, Lee H, Lim KS, Lee S, Yoon SH, Park KM, et al. Effects of HM30181, a P-glycoprotein inhibitor, on the pharmacokinetics and pharmacodynamics of loperamide in healthy volunteers. Br J Clin Pharmacol. 2014; doi:10.1111/bcp.12368.

47. Karikas GA. Anticancer and chemopreventing natural products: some biochemical and therapeutic aspects. J BUON. 2010;15(4):627-38.

48. Guo H, Wang DS, Rizwani GH, Ahmed M, Ahmed M, Hassan A, et al. Antineoplastic activity of Holoptelea integrifolia (Roxb.) Planch bark extracts (in vitro). Pak J Pharm Sci. 2013;26(6):1151-6.

49. Guo HQ, Zhang GN, Wang YJ, Zhang YK, Sodani K, Talele TT, et al. beta-Elemene, a compound derived from Rhizoma zedoariae, reverses multidrug resistance mediated by the ABCB1 transporter. Oncol Rep. 2014;31(2):858-66. doi:10.3892/or.2013.2870.

50. Lu JJ, Dang YY, Huang M, Xu WS, Chen XP, Wang YT. Anticancer properties of terpenoids isolated from Rhizoma Curcumae-a review. J Ethnopharmacol. 2012;143(2):406-11. doi:10.1016/j.jep.2012.07.009.
51. Liu J, Zhang Y, Qu J, Xu L, Hou K, Zhang J, et al. beta-Elemene-induced autophagy protects human gastric cancer cells from undergoing apoptosis. BMC Cancer. 2011;11:183. doi:10.1186/1471-2407-11-183.

52. Yao YQ, Xu YH, Lu J, Zhou HY, Wang YZ. Effect of p38 MAPK on elemeneinduced cell cycle arrest in C6 glioblastoma cells. Zhonghua Yi Xue Za Zhi. 2008;88(1):56-8 (in Chinese)

53. Brown JM, Attardi LD. The role of apoptosis in cancer development and treatment response. Nat Rev Cancer. 2005;5(3):231-7. doi:10.1038/ nrc1560.

54. Guo B, Zhai D, Cabezas E, Welsh K, Nouraini S, Satterthwait AC, et al. Humanin peptide suppresses apoptosis by interfering with Bax activation. Nature. 2003;423(6938):456-61. doi:10.1038/nature01627.

55. Chaudhry P, Srinivasan R, Patel FD. Differential expression of Fas family members and $\mathrm{BCl}-2$ family members in benign versus malignant epithelial ovarian cancer (EOC) in North Indian population. Mol Cell Biochem. 2012;368(1-2):119-26. doi:10.1007/s11010-012-1350-7.

56. Miyashita T, Krajewski S, Krajewska M, Wang HG, Lin HK, Liebermann DA, et al. Tumor suppressor p53 is a regulator of bcl-2 and bax gene expression in vitro and in vivo. Oncogene. 1994;9(6):1799-805.

57. Chen X, Wang Y, Luo H, Luo Z, Zhang T, Yang N, et al. beta-Elemene acts as an antitumor factor and downregulates the expression of survivin, $\mathrm{BCl}-\mathrm{XL}$ and Mta-1. Mol Med Rep. 2012;6(5):989-95. doi:10.3892/mmr.2012.1018.

58. Li QQ, Wang G, Huang F, Banda M, Reed E. Antineoplastic effect of beta-elemene on prostate cancer cells and other types of solid tumour cells. J Pharm Pharmacol. 2010;62(8):1018-27. doi:10.1111/j.2042-7158.2010.01135.x.

59. Zhao S, Wu J, Zheng F, Tang Q, Yang L, Li L, et al. beta-Elemene inhibited expression of DNA methyltransferase 1 through activation of ERK $1 / 2$ and AMPKalpha signalling pathways in human lung cancer cells: the role of Sp1. J Cell Mol Med. 2015;19(3):630-41. doi:10.1111/jcmm.12476.

60. Li G, Xie B, Li X, Chen Y, Xu Y, Xu-Welliver M, et al. Downregulation of peroxiredoxin-1 by beta-elemene enhances the radiosensitivity of lung adenocarcinoma xenografts. Oncol Rep. 2015;33(3):1427-33. doi:10.3892/or.2015.3732.

61. Xu HB, Li L, Fu J, Mao XP, Xu LZ. Reversion of multidrug resistance in a chemoresistant human breast cancer cell line by beta-elemene. Pharmacology. 2012;89(5-6):303-12. doi:10.1159/000337178.

62. Gottlieb E, Armour SM, Harris MH, Thompson CB. Mitochondrial membrane potential regulates matrix configuration and cytochrome $\mathrm{c}$ release during apoptosis. Cell Death Differ. 2003;10(6):709-17. doi:10.1038/ sj.cdd.4401231.

63. Lowe SW, Ruley HE, Jacks T, Housman DE. p53-dependent apoptosis modulates the cytotoxicity of anticancer agents. Cell. 1993;74(6):957-67.

64. Sui X, Kong N, Ye L, Han W, Zhou J, Zhang Q, et al. p38 and JNK MAPK pathways control the balance of apoptosis and autophagy in response to chemotherapeutic agents. Cancer Lett. 2014;344(2):174-9. doi:10.1016/j. canlet.2013.11.019.

65. Elias J, Dimitrio L, Clairambault J, Natalini R. The p53 protein and its molecular network: modelling a missing link between DNA damage and cell fate. Biochim Biophys Acta. 2014;1844(1 Pt B):232-47. doi:10.1016/j. bbapap.2013.09.019.

66. Saha MN, Qiu L, Chang H. Targeting p53 by small molecules in hematological malignancies. J Hematol Oncol. 2013;6:23. doi:10.1186/1756-8722-6-23.

67. Wang JQ, Du ZW, Gao XF, Wu M, Zhang YC, Pan Y, et al. The effect of BCl-2 gene silencing on the sensitivity of cell line A549 to chemotherapeutic drugs. Zhonghua Jie He He Hu Xi Za Zhi. 2013;36(3):191-7 (in Chinese)

68. Hu J, Jin W, Yang PM. Reversal of resistance to adriamycin in human breast cancer cell line MCF-7/ADM by beta-elemene. Zhonghua Zhong Liu Za Zhi. 2004;26(5):268-70 (in Chinese)

69. Li QQ, Lee RX, Liang H, Wang G, Li JM, Zhong Y, et al. beta-Elemene enhances susceptibility to cisplatin in resistant ovarian carcinoma cells via downregulation of ERCC-1 and XIAP and inactivation of JNK. Int J Oncol. 2013;43(3):721-8. doi:10.3892/ijo.2013.1996.

70. Li QQ, Wang G, Liang H, Li JM, Huang F, Agarwal PK, et al. beta-Elemene promotes cisplatin-induced cell death in human bladder cancer and other carcinomas. Anticancer Res. 2013;33(4):1421-8.

71. Li QQ, Wang G, Huang F, Li JM, Cuff CF, Reed E. Sensitization of lung cancer cells to cisplatin by beta-elemene is mediated through blockade of cell cycle progression: antitumor efficacies of beta-elemene and its synthetic analogs. Med Oncol. 2013;30(1):488. doi:10.1007/ s12032-013-0488-9. 
72. Ward A, Shukla K, Balwierz A, Soons Z, Konig R, Sahin O, et al. microRNA519 a is a novel oncomir conferring tamoxifen resistance by targeting a network of tumor-suppressor genes in ER+ breast cancer. J Pathol. 2014;. doi:10.1002/path.4363.

73. Zhang B, Zhang X, Tang B, Zheng P, Zhang Y. Investigation of elemeneinduced reversal of tamoxifen resistance in MCF-7 cells through oestrogen receptor alpha (ERalpha) re-expression. Breast Cancer Res Treat. 2012;136(2):399-406. doi:10.1007/s10549-012-2263-6.

74. Wang Z, Xia Q, Cui J, Diao Y, Li J. Reversion of P-glycoprotein-mediated multidrug resistance by diallyl trisulfide in a human osteosarcoma cell line. Oncol Rep. 2014;31(6):2720-6. doi:10.3892/or.2014.3154.

75. Fu TH, Li JY, Jing YY, Sun PJ, Bai X. Effect of elemene on reversing chemoresistance to adriamycin in human stomach cancer cell line. Zhong Yao Cai. 2013;36(4):601-3 (in Chinese)

76. Zhu TZ, Li XM, Luo LH, Song ZQ, Gao X, Li ZQ, et al. beta-Elemene inhibits stemness, promotes differentiation and impairs chemoresistance to temozolomide in glioblastoma stem-like cells. Int J Oncol. 2014;45(2):699-709. doi:10.3892/ijo.2014.2448.
77. Zhu TZ, Li XM, Luo LH, Xu YH, Cao P, Liu Y, et al. beta-Elemene inhibits proliferation through crosstalk between glia maturation factor beta and extracellular signalregulated kinase $1 / 2$ and impairs drug resistance to temozolomide in glioblastoma cells. Mol Med Rep. 2014;10(2):1122-8. doi:10.3892/mmr.2014.2273.

78. Cai DY, Gao X, Wu XH, Hong TT. Synergistic effect of beta-elemene injection combined paclitaxel injection on human breast cancer MB-468 cells: an in vitro study. Zhongguo Zhong Xi Yi Jie He Za Zhi. 2013;33(7):978-82 (in Chinese)

79. Zhang F, Xu L, Qu X, Zhao M, Jin B, Kang J, et al. Synergistic antitumor effect of beta-elemene and etoposide is mediated via induction of cell apoptosis and cell cycle arrest in non-small cell lung carcinoma cells. Mol Med Rep. 2011;4(6):1189-93. doi:10.3892/mmr.2011.537.

\section{Submit your next manuscript to BioMed Central and take full advantage of:}

- Convenient online submission

- Thorough peer review

- No space constraints or color figure charges

- Immediate publication on acceptance

- Inclusion in PubMed, CAS, Scopus and Google Scholar

- Research which is freely available for redistribution

Submit your manuscript at

www.biomedcentral.com/submit

(O) Biomed Central 